\title{
ON THE DESIGN OF THE AUTOMATED MONITORING SYSTEM OF WASTE DISPOSAL OBJECTS WITH THE APPLICATION OF EARTH REMOTE SENSING TECHNOLOGIES
}

\author{
Maretta Kazaryan \\ North Ossetian State Medical Academy \\ e-mail:marettak@bk.ru
}

\begin{abstract}
Keywords: Earth remote sensing, satellite monitoring, WDA, software, spatial data processing.
\end{abstract}

\begin{abstract}
Currently, geographic information systems have taken strong positions in economics, politics and in almost all spheres of human activity. The result of human activity in urbanized areas is the emergence and further spread of unauthorized landfills and industrial waste. In order to timely intervene and stop the spread of foci of infection and changes in the soil composition, it is necessary to have an automated system for monitoring the disposal facilities and industrial waste.

The purpose of the work is to design a model of an automated system for monitoring waste disposal sites, including industrial sites, using remote sensing technologies.

General research methodology: The paper uses modern methods of information systems design, using the theory of databases, data warehouses, and geographic bases data.

Scientific novelty: The paper suggests a model of an automated space system monitoring for the presence of waste disposal facilities. A general methodology for constructing a geoinformation model that monitors territories for the presence of waste disposal sites and also a methodology for the development of geodatabase are given. Landfill geo-databases are a structure of attribute and geographic data obtained in an automated mode. An analysis of current perspectives in the creation and operation of such automated geo-information systems is given using specific knowledge in the field of very large, distributed and open data archives. As a realization of theoretical reasoning, the practical part of the formation of software, technical and mathematical support of the remote monitoring system of the waste disposal area (WDA) and industrial waste (IW) landfill is given. In general, the work is survey-research in nature.
\end{abstract}

\section{Introduction}

Let us consider the ideology of creating a system for remote monitoring of waste disposal facilities (WDF), including industrial (IW) - (SRM_WDF-IW). It should be noted that such studies are actively conducted abroad [5-12, 30-32], as well as in the leading specialized research institutes of our country [3-5] and the same topic is often published in mass media including the Internet. 
The relevance of research in the field of application of Earth remote sensing technologies is obvious. This is due to the range of problems created by the emergence of unauthorized WDAs and software, as well as the resulting consequences in all spheres of human activity.

By the order of the Government of the Russian Federation of August 21, 2006, N 1157-p the Concept of creation and development of the spatial data infrastructure of the Russian Federation is approved [1]. The concept defines that the creation and development of the spatial data infrastructure of the Russian Federation is due to the objective needs of citizens, organizations, government bodies and local governments in the effective use of reliable, operational and relevant spatial data. By spatial data here is meant some digital information (form, location, properties) about WDA and software defined in the coordinate-time frame of reference. Under the basic spatial data we will understand the spatial data that are allowed for open publication in mass media; they have a steady spatial position in the coordinate-time frame of reference. This makes it possible to orient other features to them. Metadata is information that describes the volume, content, and other characteristics of spatial data.

The concept notes: «The currently existing systems for identifying spatial objects by their address description, including registers, inventories, registers maintained by federal executive authorities, do not allow the integration and sharing of spatial data obtained from various sources. The result was the absence in the Russian Federation of a single system for identifying spatial objects; this fact prevents the use of spatial data as a universal communication element for various databases and makes it impossible to build a single information space of the country. The currently existing systems for identifying spatial objects by their address description, including registers, inventories, which are maintained by federal executive authorities, do not allow for the integration and sharing of spatial data obtained from various sources. The result was the absence in the Russian Federation of a unified system of identification of spatial objects, which prevents the use of spatial data as a universal communication element of various databases and makes it impossible to build a single information space of the country». following:

The creation of spatial data infrastructure will allow providing the

1. improvement of the quality and efficiency of management at the state and municipal levels due to the wide use of information resources of spatial data when making management decisions and monitoring their implementation;

2. provision of the up-to-date and reliable information on basic spatial data to consumers according to uniform rules and tariffs;

3. reduction of budget expenditures on the creation of spatial data in general, improving their quality by eliminating duplication of work on the creation of spatial data; 
4. encouragement of investments in the creation of spatial data and related information services.

As it is noted in the article by B. A. Dvorkin [2]: "The rapid development of computer technologies, the emergence of the Internet, the emergence of desktop geo-information applications, and the active introduction of location services (socalled LBS) into the daily life based on satellite navigation systems led to the fact that spatial data is increasingly becoming a constant attribute of our daily life. If relatively recently, the main source of spatial data was topographical survey, now space imagery, aerial photography from unmanned aerial vehicles, laser scanning, etc. are coming to the fore. Now any organization, any private user, has had the opportunity to create their own maps and applications thanks to easy access to spatial data, as well as to a wide range of image processing, analysis and visualization programs."

From the reasoning given in article [2], we can draw the following conclusions:

1. there is an objective need for the creation and development of an information infrastructure of spatial data, both at the federal, regional and municipal levels;

2. spatial data, the infrastructure of their creation and development are one of the most important links in the digital transformation of the country's economy.

Particular attention should be paid to the problem of identifying unauthorized storage sites for solid household waste and industrial waste (SHW and IW), monitoring the correct operation of existing landfills for SHW and IW in accordance with current legislation, and assessing their impact on the environment. This problem has become so acute for Russia that Russian President Putin V.V. drew attention to it, calling it a "garbage disaster" of Russia https://lenta.ru/news/2016/04/14/musor/.

There is a great need for environmental protection systems to use spatial data based on the technologies of remote sensing of the Earth from space [14-29].

Below are examples of the application of the technology of remote sensing of the Earth from space to meet some of the needs of the environmental protection system in the area of storage of solid waste and industrial waste. 


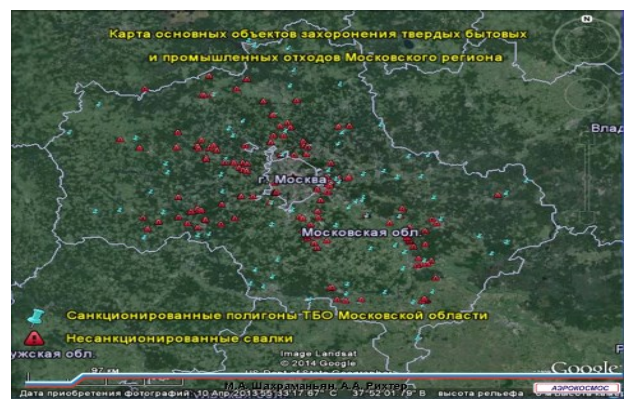

Fig. 1. Detection of unauthorized landfills

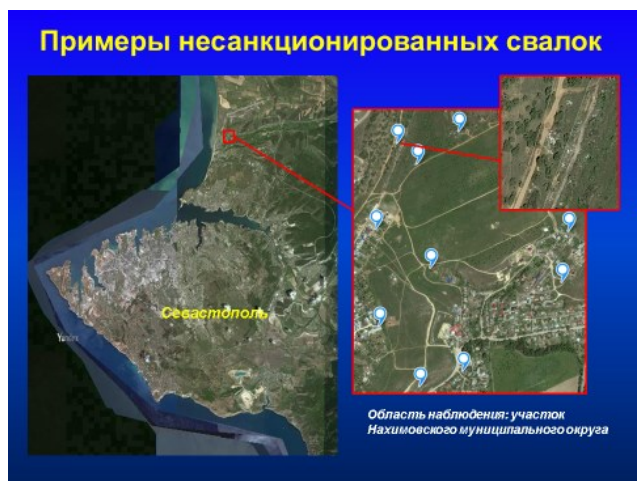

Fig. 3. Detection of unauthorized solid landfills in Sevastopol

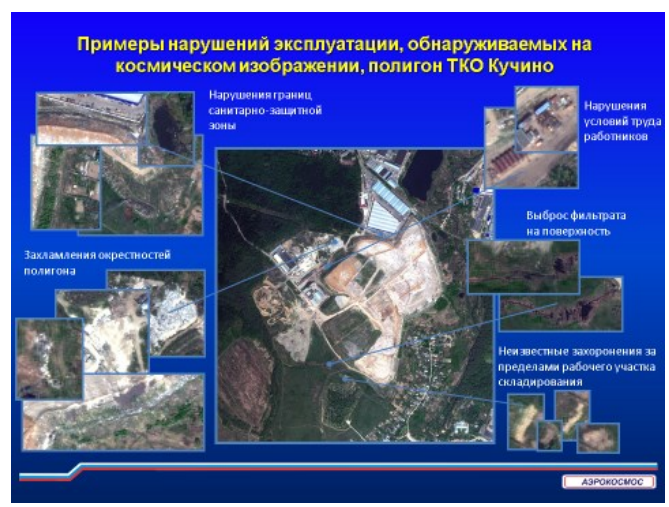

Fig. 5. Monitoring violations storage of waste

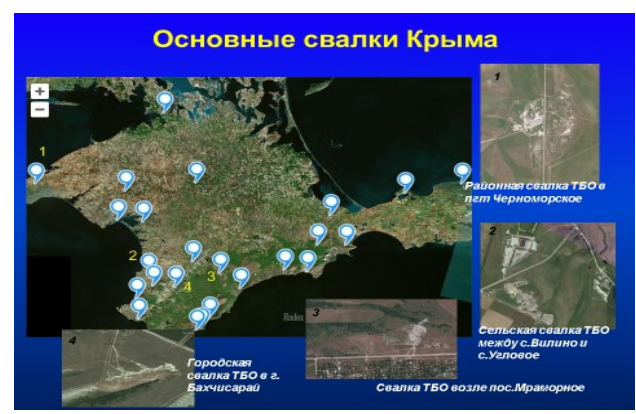

Fig. 2. Main dumpsites of the Crimea

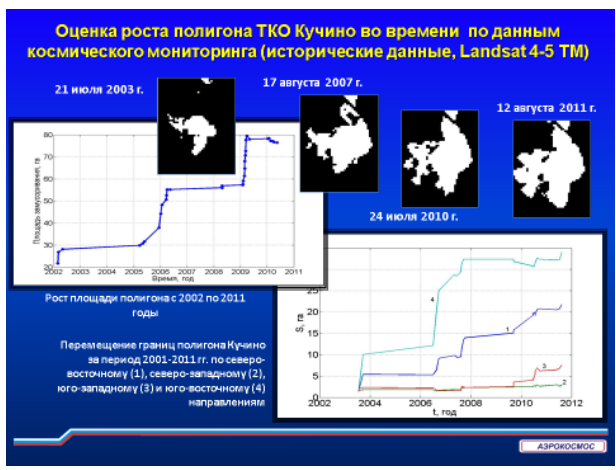

Fig. 4. Assessment of the growth of the landfill of municipal waste in Kuchino

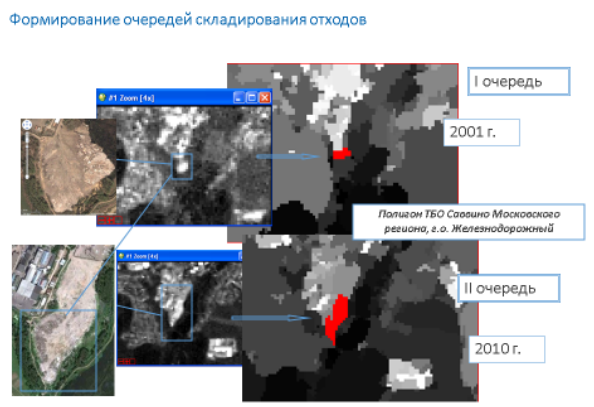

Fig. 6. Queuingcontrol from the operation of the SW landfill in Kuchino 
Выполнение требования «Расстояние до ближайшихградостроительных объектов»

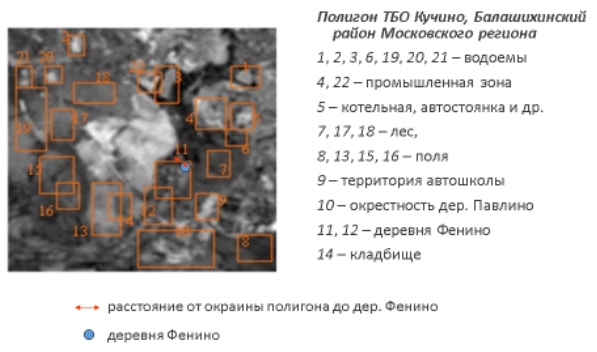

Fig. 7. Execution control of requirements for sanitary zones

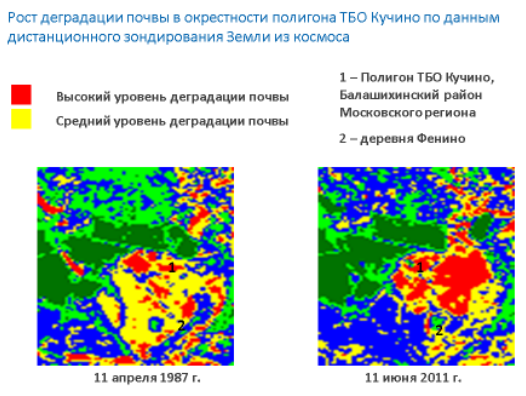

Fig. 8. Control of soil degradation in the area Kuchino landfill

The geography of our country and, in particular, of the North Caucasus is characteristic of lands that are difficult to access for field studies. To solve the problems associated with the detection of unauthorized waste disposal sites (WDS) and industrial waste (IW), it is necessary to conduct the remote sensing methods and then field studies confirming the results. The interest of the authorities responsible for the timely prevention of accumulations of solid household waste (SHW), which have inevitable consequences both in the field of sanitary epidemiological and other areas of the socio-economic and medical-biological state of the region, is also obvious.

It should be noted that in recent years the number of spacecraft (SC) has increased in the world. This contributes to an increase in the frequency and volume of information necessary for further processing. For our task, namely, environmental monitoring for the presence of WDS and IW - means the possibility of detecting some negative consequences at the early stages of the appearance of unauthorized dumps, and this is essential.

Information received from the space station, which was previously classified as t6his sphere was actively used and is now used in the military-defense industry, became more accessible. It is quite possible to receive space images (SI) in open access on the Internet, using various technologies. The availability of information has also increased on the subject of research - WDS and IW, which contributes to the use of satellite information without creating specialized additional centers for the accumulation of primary information and this is an additional cost savings and increase in the profitability of the system. This fact may lead to the creation of its own very large archives of satellite information on the subject of WDS and IW. 


\section{Research part}

Creating of a monitoring system for waste disposal facilities as well as industrial waste requires the implementation of certain requirements - these are the basic elements of a monitoring system (MS). Regardless of the type of MS, these elements are represented in the performance of certain actions with space information. The typical tasks that are part of the system for processing, storing and using space information are the following [29]:

1. receiving and collecting of space information in the automated mode;

2. storing information in archives, respectively, supporting and organizing them;

3. information processing in an automated mode;

4. transfer of information to users, including remotely;

5. use of the processed space information of a specific MS, in our case, MS_WDS and IW;

6. management and control of the relevant units MS_WDS and IW.

In carrying out all of the above tasks, software systems with a high level of automation, the ability to use distributed network technologies, etc. are used.

Let us consider the issues related to the development of software for the organization of automated reception and collection of satellite data.

We are investigating the task of creating software for the monitoring system of WDS and IW according to remote sensing data; first of all, we study the situation with the collection and reception of space information. Based on modern realities, namely, on open (relatively) access to the storage bases of the SI through the Internet, it makes it possible to create specialized centers for receiving and processing SI. All information on the SI from everywhere, including various funds of research projects, will be sent to these centers. To solve such a problem, you must have multifunctional utilities and programs for processing various SI and obtaining information for processing and monitoring territories for the presence of WDS and IW.

Let us consider the task of creating an automated system for archiving satellite data. Any automated system of this type should have a unit for maintaining satellite data archives, the main purpose of which is to store and provide the SI to users in local and remote operation.

To automate this monitoring system block, it is necessary to use a DBMS with embedded SQL language that allows you to work in software mode, having a friendly computer program interface, or using a SQL query system to implement a range of tasks related to searching and retrieving the necessary SI series. The information storage unit should have the following properties:

with time;

a. adaptability to all types of satellite information, which can be modified

b. users work in remote access mode; 
c. the maximum automation of the preliminary storage stages of the SI is the annotations, archiving and the storage process itself in the database;

d. this system should be open in terms of replenishment with new SIs and, accordingly, modification of technical means (servers, etc.) allocated for archives;

e. and, as a rule, separate geographically distributed centers should exist in the country as information repositories and, accordingly, certain nodes of the open Internet system, physical information carriers (CDs, etc.).

Fig. 9 shows the architecture model of the automated SI archive.

We give some comments on each block of this model.

The first block of the archiving system includes databases on all types of information, i.e. by data directory, file storage and long-term file storage. The archives of WDS and IW space data are presented in the form of a software package, which is updated depending on the tasks of interest to users and, accordingly, researchers.

The second block - the archive administration system includes archiving utilities, work with data, as well as the selection of necessary information for processing and supporting users' orders. In the management plan of the unit, a group of operators responsible for the front of the system is attached.

The third block is the availability of archiving systems via the Internet, i.e. relevant websites. This system includes user web-interfaces, as well as service web-interfaces. The work on managing this block is performed by operators and users who are competent in terms of information culture.

The fourth block is system control. It includes checking web-interfaces, email notification of various emergency situations, checking the technical condition of computers and automatic launching of special utilities - tests of the storage system of the CS as a whole. This system is open, i.e. utilities are replenished with a variety of application programs that improve the quality of the QS and modify the methods of storing them in the information repositories. 


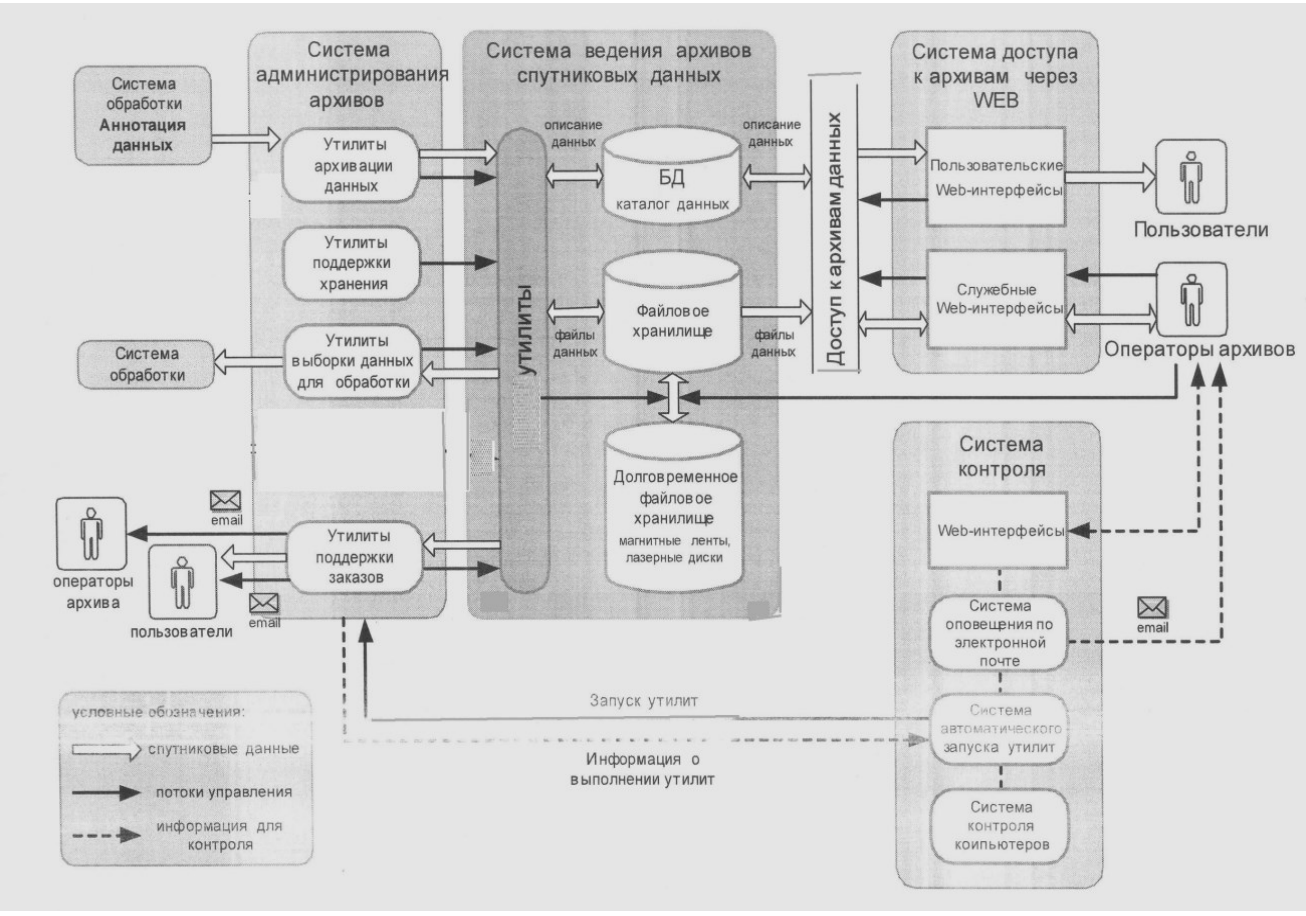

Fig. 9. Model of the system of automated archiving of the SIs when monitoring territories for WDS and $I W$

So, we have a description of the model of WDS and IW remote monitoring using information systems that ensure the work with super-large, distributed and replenished storages of satellite images.

Let us investigate the issue related to the space information processing system. Processing of space information is represented in the form of primary and thematic data processing. The implementation of this work is carried out in two modes - automatic and automated.

In the first case, a software package is developed; a system of macros is used, for writing of which an interface is provided. It provides a mode of remote access to information.

In the second case (automated), a sequential chain of information processing is created, forming data streams and parallelizing the processing of space data. At the same time, tasks for workstations are formed; their work is monitored, which leads to an increase in production capacity. At any time you can increase the number of workstations, etc.

Now let us investigate the issue related to the integration of the results of the processing of space data with the diverse information used in the WDS and IW monitoring system. 


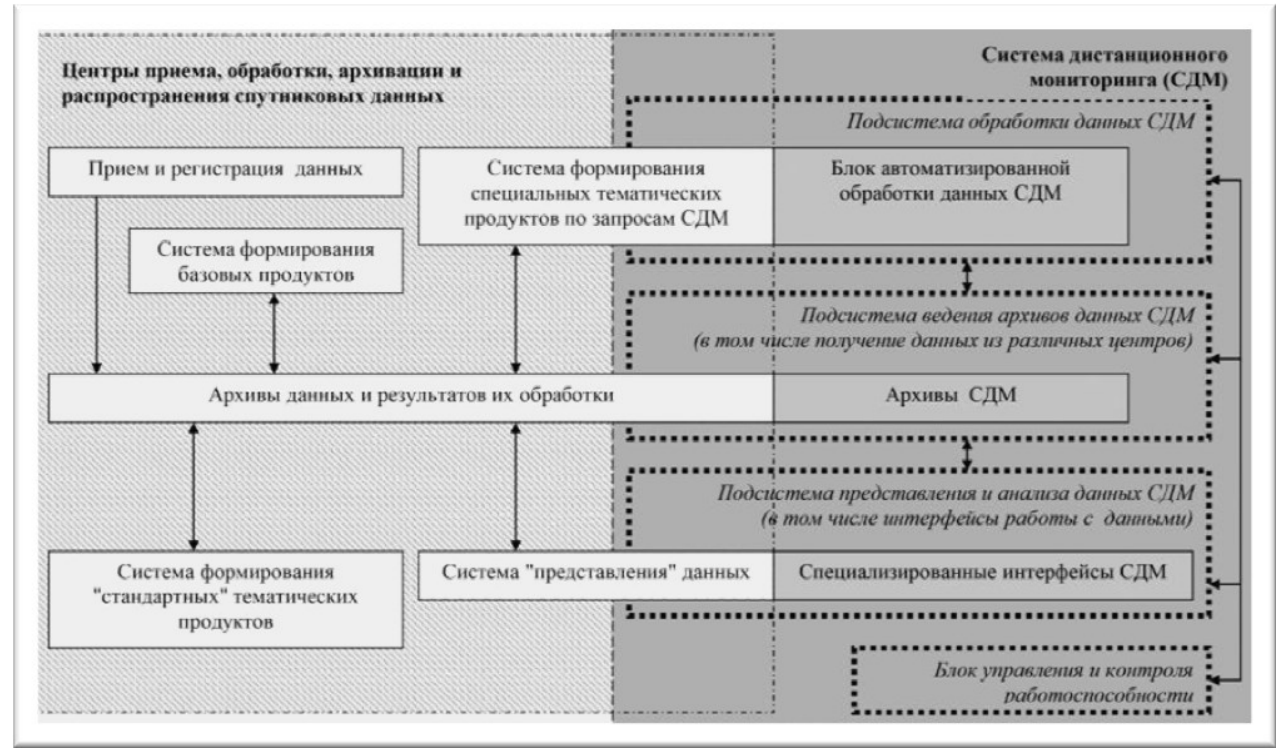

Fig. 10. The basic scheme of RMS WDS-IW formation

Provides the GIS. This option of work demands additional expenses for resources. This method is used when the monitoring system is not created from scratch. An additional unit with satellite information is inserted into the system. Therefore, a mechanism is needed that allows satellite data to be exported to GIS and inserted into its archives.

Let us consider the second approach. In the GIS, inquiries are made to obtain the necessary information from the corresponding archives of space data. In GIS, interfaces are implemented that allow combining heterogeneous information.

This approach, which is widely used nowadays, simplifies issues related to maintaining distributed SIs archives and updating information received from a spacecraft.

Let us consider the basic principles of modern remote monitoring systems (RMS), in particular WDS-IW.

Fig. 10 proposes a basic scheme for building RMS WDS-IW.

From this figure it follows that the RMS includes the following main blocks: data processing; archiving; data presentation and analysis; management and performance monitoring.

Let us consider the operation of the main blocks of the system, presented in Fig. 10. Modern realities in the field of Earth remote sensing are such that the preliminary processing of space information goes into a new category - the formation of basic products. Basic information products have a number of qualitative properties that allow for thematic processing of a SI without serious 
consequences - a stable radiometric calibration, illumination, state of the atmosphere, geographical and temporal reference, etc. The modern user of the SI is interested in obtaining information in the form of basic products. In exceptional cases, to obtain thematic products used in our case when monitoring territories for the presence of WDS-IW, data processing systems are created.

Recently, a definite situation has developed regarding the implementation of the RMS and the work of its individual units. The equipment necessary for the operation of these units is provided to space information receiving and processing centers. In such situations, the speed of information processing increases, since there is no need to transfer data in large volumes from the centers to the RMS.

There is a tendency to maximally automate the processing of information during the implementation of RMS, and accordingly, based on this, the work of the thematic processing unit for SI in various information systems is organized in a certain way.

We have to deal with situations related to the fact that the implementation of various processes for the processing of space information uses a variety of software environments, and perhaps also different operating systems. It is necessary to organize the interaction of these procedures and control over their implementation.

The introduction of distributed computing resources requires different approaches for their correct application in the processing of remote sensing data.

The data archiving subsystem is one of the key elements of any RMS. Above, we have described this block in detail and its principle of operation (see Fig. 9).

The information presentation and analysis subsystem is undoubtedly one of the most important elements of any RMS.

Let us consider the main factors shaping this subsystem.

The first factor affecting the formation of a system is the provision of a distributed user of space information and tools for its analysis in order to ensure remote monitoring. To perform this function, it is necessary to have a webinterface - this is a modern trend in the development of information systems. The advantages of these interfaces are that there is no need to purchase and maintain a significant number of licenses, as is done for desktop applications, the same GIS.

The second factor is the involvement of various Internet technologies for the development of complex tools in the implementation of distributed data analysis in RMS.

The third factor is the possibility of online access to data from external information systems, as well as to the resources of suppliers of remote sensing data.

And finally, speaking of the RMS control and operability control unit, it is important to note that an increase in the level of automation of health monitoring 
processes is required, as well as the creation of technologies for the automated detection and diagnosis of faulty situations.

\section{Practical part}

As a realization of the above theoretical considerations, we present the following practical part on the formation of software, technical support of the remote monitoring system of the WDS and $I W$.

The complex for receiving satellite information assumes the presence of the following equipment:

- UniScan - 36 (ScanEx manufacturer);

- Data processing server (2 pcs.) by HP;

- Cluster data storage systems (2 pcs.);

- Work stations (4 pcs.);

- Local area network (10 G; speed $10 \mathrm{Gbit} / \mathrm{C})$;

The software of the system also includes:

- data reception (software developed by ScanEx);

- preprocessing software for different satellite systems (TERRA / AQUA for MODIS; SuomiNPP / NOAA-20 for NIIRS, CrIS, ATMS; Fengyun - 3A / B / $\mathrm{C}$ for MERSI). Linux / CentOS operating system on one server and every 15 minutes run snapshot processing scripts;

- for thematic processing using two servers. Each TERRA / AQuA received by the SI is generated into a set of multiscale multichannel images and this information is immediately displayed on the web page. Next, the application programs are performed to decrypt the image for the presence of WDS and IW (NDVI calculation, cloud masking, etc.).

The presence of high-performance computing systems (clusters) is assumed:

ArmCluster computing system (http://www.cluster.am): computing field of 128 cores $(64 \times 2$ Intel Xeon $3.06 \mathrm{GHz}, 2$ GB RAM), computing network Myrinet, control network - Gigabit Ethernet, computing system ArmGrid (http://www.grid.am): computational field of 368 cores $(30 \times 2$ Intel Quad Core Xeon E5420 2.5GHz, RAM $8 \mathrm{~Gb}$ ), computer network - Gigabit Ethernet, control network - Gigabit Ethernet $+32 \times 2$ Intel Quad Core Xeon E5405 2.0 GHz, RAM $8 \mathrm{~Gb}$ ), computer network - Infiniband, control network - Gigabit Ethernet, PhiCompute computing system: computing field 48 CPU cores $(2 \times 2$ Intel Xeon E5-2680 v3, 128 GB RAM $)+244$ Phi cores $(2 \times 2$ Intel Xeon Phi 7120), 10 GbE computing network managing I have a network-Gigabit Ethernet.

Servers:

Application servers: $2 \times$ HP DL380p Gen8, 2 x Intel Xeon E5-2620v2, 128 GB RAM, $8 \times 600$ GB 6G SAS 10k HDD. 
GPGPU server: HP DL380p Gen8, $2 \times$ Intel Xeon E5-2620v2, 128 GB RAM, $3 \times 600$ GB 6 G SAS 10k HDD, NVIDIA Tesla k40, management server: HP DL380p Gen8, Intel Xeon E5-2620v2, 32GB RAM, $3 \times 600$ GB 6G SAS 10k HDD.

Data Warehouses:

QNAP TS-809U-RP network storage, storage capacity up to $48 \mathrm{~TB}$

IBM x3650 network media storage, storage capacity up to 12 TB.

HP MSL2024 tape library, storage capacity up to $360 \mathrm{~Tb}$.

Workstations:

Dell T5500 Workstation with NVIDIA Tesla C1060 GPGPU

Dell T3500 Workstation graphics station with two ATI FirePro V5900 graphics cards.

When working on the creation of RMS WDS-IW, free or free software will be used, as well as proprietary software systems.

Consider some of the development in relation to software that is developed in the basic utilities of the system.

1. The adaptation of existing image processing algorithms to the problem of research [14-29]. These algorithms include:

- affine transformations over the image (rotation, shift, scaling);

- image enhancement;

- selection of objects;

- filtering according to the spectrum and size of objects, dilatation, erosion, opening, closing, morphological processing of images (selection of boundaries, filling of areas, selection of connected components);

- clustering and classification by methods of K-intragroup averages and ISODATA, etc.

These algorithms are adapted to the characteristics of the WDS: size, distribution, component composition, spectral composition, characteristics of the environment.

2. Development of special image processing algorithms for the detection and analysis of WDS [14-29]. These algorithms include:

- algorithms for splitting a time series of images into a time series of sections of these images;

- algorithms for the detection of texture components in the composition of the WDS and the environment;

- algorithms for assessing the morphological composition of the components of WDS;

- special training algorithms to detect WDS;

- algorithms for obtaining component landfills as part of the WDS and its surrounding natural environment;

- algorithms for obtaining relief WDS on a pair of images; 
- algorithms for assessing the dynamics of changes in the surface and body of the WDS and its main geometric characteristics;

- algorithms for assessing chemical processes occurring in landfills;

- algorithms for the classification of WDS according to the data of space images;

- algorithms for calculating the linearity of polygonal objects;

- algorithms for evaluating component, temperature, vegetative, technological, and other characteristics of the WDS.

3. Study of the state of the soil and vegetation [14-29]. Algorithms for assessing the degree of soil degradation. The basis of these algorithms is the calculation. To study the state of the soil and vegetation, special indices of vegetation response have been developed depending on those or other influencing factors. Factors, vegetation reaction indices and the degree of soil degradation are presented in normalized form. At the same time, the factors themselves are ranked according to the degree of importance. This method of assessing the degree of soil degradation is the cheapest because does not require additional archival data, like most other methods for assessing soil degradation. In addition, it is fast-acting, although less accurate, and allows us to estimate the tendency of the soil not only to degradation, but also to recovery. The state of the soil is also determined by assessing the yield of the soil, since in most cases, landfills are located in close proximity to rural areas. To assess the yield of the soil, many algorithms based on multiple regression have been developed and implemented.

4. Evaluation of the geometric characteristics of the WDS [14-29].

The algorithms for estimating the geometric characteristics of the WDS are divided into algorithms for planar and spatial characteristics. A single image is used to estimate the plane characteristics, and a stereo pair is used to estimate the spatial characteristics. To assess changes in geometric characteristics, a time series of images of one territory is used. Planar geometrical characteristics include area, perimeter, polygonal region, contour and contour traversal, linearity, ellipticity, center of mass, scattering coefficient, planar parameters of components. The spatial geometrical characteristics include the volume, spatial parameters of the components, and the body of the WDS, the relief of the surface, the slope coefficient, the average height of the WDS, the number of tiers. The change in geometric parameters is divided into average and direction. The direction is given by a vector on a plane for plane parameters and a vector in space for spatial parameters. The change in parameters is characterized by speed, i.e. increment parameter per unit of time. By changing the parameters, you can make a short-term forecast of future values of geometric parameters.

5. Development of attribute databases [14-29]. Attribute databases are developed in database management systems. Structurally, they consist of a set of tables connected to each other through special link tables. Different tables characterize objects of different types. Attribute databases have been developed: on 
general information of the WDS, on individuals and legal entities associated with them, on administrative-territorial units, on the component composition of the WDS, on the spectral characteristics of the WDS, on space images and metadata snapshots, etc. Each database has its own data scheme, and all developed databases are combined into a data warehouse. To manage each database, special programs have been developed in which the procedures of creation, opening, closing, updating, updating, etc. are implemented. To integrate databases into a data warehouse and to manage this storage, programs are also implemented in special software environments. Each the database and the data warehouse itself have their own interface, which allows managing databases interactively. Descriptions of databases and data storage are developed. The source data for reading the database are normalized. Some of them were obtained using programs from textual information taken from various sources. The other part is calculated according to the algorithms for detection and analysis of WDS.

\section{Conclusion}

The paper proposes the design and further use of an information system for the implementation of remote monitoring using remote sensing methods and technologies. Here we consider the features and trends in the development of modern geographic information systems in certain thematic areas, in our case, we consider WDS-IW. The article is of an overview and methodological nature. An analysis of current perspectives in the creation and operation of such automated geo-information systems is given using specific knowledge in the field of very large, distributed and open data archives. As a realization of theoretical reasoning, the practical part of the formation of software, technical and mathematical support of the remote monitoring system of the WDS-IW is given.

\section{References}

1. Order of the Government of the Russian Federation of 21.08.2006, N 1157-p.

2. Dvorkin, B. A. Spatial data infrastructure: a regional aspect. Journal of Geomatics, 2014, $1,17-22$.

3. Tolpin, V. A., Balashov I. V., Efremov V. Yu., Lupyan E. A., Proshin A. A., Uvarov I. A., and Flitman E. V. Creating interfaces for working with data of modern remote monitoring systems (GEOSMIS system). Modern problems of remote sensing of the Earth from space. 2011, 8, 3, 93-108.

4. Tolpin, V. A., Lupyan E. A., Bartalev S. A., Plotnikov D. E., and Matveev A. M. Opportunities for analyzing the state of agricultural vegetation using the VEGA satellite service. Optics of the Atmosphere and the Ocean. 2014, 27, 7, 306, 58186.

5. Uvarov, I. A., Matveev, A. M., Burtsev, M. A., Lupyan, EA, Mazurov, A. A, Proshin, A. A., Savorsky, V. P., and Sudneva, O. A. Organization of distributed work with 
satellite hyperspectral data for solving scientific and applied problems. Modern problems of remote sensing of the Earth from space. 2014, 11, 1, 322-33.

6. Acker, J. G., and Leptoukh G. Online analysis of the use of NASA earth science data. Eos, Transactions American Geophysical Union, 2007, 88, 2, 14-17.

7. Asrar, G., and Greenstone, R., 1995. MTPE EOS Reference Handbook. NASA Goddard Space Flight Center.

8. Budget Activity: National Environmental Satellite, Data, and Information Service. 2012. http://www.corporateservices.noaa.gov/nbo/fy13_presidents_budget/7_NESDIS.p df

9. Interoperable Catalog System Valids, CEOS / WGISS / ICS / Valids, Issue: 1.2, April $2005,55 \mathrm{p}$.

10. Lavrova, O. Yu., Loupian E. A., Mityagina M. I., Uvarov I. A., and Bocharova T. Yu. Multi-User Guidelines for Satellite Remote Sensing Data. Bollettino di Geofísica teorica ed applicata. An International Journal of Earth Sciences. 2013, 54, 146-47.

11. Loupian, E. A, Mazurov A. A, Flitman E. V., Ershov D. V., Korovin G. N., Novik V. P., Abushenko N. A., Altyntsev D. A., Koshelev V. V., Tashchilin S. A., Tatarnikov A.V., Csiszar I., Loboda T., Sukhinin A. I., Ponomarev E. I., Fonin S. V., Belov V. V., and Matvienko G. G. Satellite Monitoring for Global Change. 2006, 11, 1, 113-45.

12. Moore, R. T., Hansen M. C. Google Earth Engine: a new cloud-computing platform for global-scale earth observation observation and analysis. AGU Fall Meeting Abstracts, 2011, 1, 2 p.

13. Ramapriyan, H. K. Hazard Science Data. CENDI / NFAIS Workshop on Repositories in Science \& Technology: Preserving Access to the Record of Science November 2011,30 .

14. Shakhramanyan, M. A., Kazaryan M. L, etc. Space monitoring of the state of the environment for the development of a system of additional environmental education”. Modern problems of science and education. 2015.- №3.

15. Shakhramanyan, M. A., Richter, A. A., and Kazaryan, M. L., Automation of the Detection and Disposal of Waste Disposal Objects, Fundamental Research, 2015, 8 (Part 2), 281-86.

16. Shakhramanyan, M. A., Richter, A. A., and Kazaryan, M. L Cosmic image processing using multimedia and its application in space monitoring of waste disposal sites. Basic Research, No. 8 (Part 2) 2015, 328-32.

17. Richter, A. A., Shakhramanyan M. A., and Kazaryan M. L. The method of visual detection in the task of space monitoring of waste disposal facilities. Bulletin of the Vladikavkaz Scientific Center. 2015, 15, 3, 61-67.

18. Shakhramanyan, M. A., Richter, A. A., and Kazaryan, M. L., Estimation of Geometric Parameters of Littering Areas from Multispectral Space Images, Fundamental Research, 2015, 2, (part 13), 2866-70.

19. Shakhramanyan, M. A., Richter A. A., Kazaryan M. L. Development of a method for assessing the degree of soil degradation based on long-term observation data. Basic Research, 2015, 2 (part 14), 3095-99.

20. Shakhramanyan, M. A., Kazaryan M. L., Richter A.A. Identification of foci of littering according to low-resolution satellite images Landsat. Information and space, 2016, $3,91-96$. 
21. Shakhramanyan, M. A., A. A. Richter, and M. L. Kazaryan. The method of automating the assessment of underlying surface indices and their changes over time using space images and its application in assessing the state of the environment in the vicinity of solid waste landfills. Bulletin of Tomsk Polytechnic University. Engineering georesources. 2016, 327, 8, 52-58.

22. Shakhramanyan, M. A., Richter A. A., and Kazaryan, M. L. Methodology for automatic detection of components of waste disposal facilities from space images. News of the Tomsk Polytechnic University, Engin. of georesources, 2017, 328, 3, 46-5.

23. Kazaryan, M. L., M. A. Schahramanian, and A. A. Richter, Future Space monitoring of the Earth and the Haar wavelet transform.

24. Schahramanian, M. A., A. A. Richter, and M. L. Kazaryan Evaluation of chemical process parameters in waste disposal sites by satellite images. Ecological Engineering and Environment Protection, 2017, 1, 22-28.

25. Schahramanian, M. A., A. A. Richter, and M. L. Kazaryan Pattern recognition algorithm using descriptors combined radio and visible spectra. Proc. SPIE Vol. 10221, Mobile Multimedia/Image Processing, Security, and Applications, 1022107 (2017) DOI:10.1117/12.226287.

26. Schahramanian, M. A., A. A. Richter, and M. L. Kazaryan. Information modeling of waste disposal sites. Ecol.1 Engineering and Envir. Protection, 2017, 1, 15-21.

27. Schahramanian, M. A., A. A. Richter, M. L. Kazaryan Space Monitoring of the Earth on the Presence of Solid Domestic Wastes Using a Discrete Orthogonal Transforms. Serbian journal of electrical engineering. 2017, 14, 3, 343-64.

28. Kazaryan, M. L., Shakhramanyan M. A, and Voronin V. The automated spacemonitoring system of waste disposal sites. Proc. SPIE Remote Sensing, Proceedings Volume 10793, Remote Sensing Technologies and Applications in Urban Environments III, 1079318 (9 October 2018); DOI:10.1117/12.2500059 Event: SPIE Remote Sensing, 2018, Berlin, Germany.

29. Kazaryan, M. L. Space monitoring of solid domestic waste and industrial waste disposal facilities (MSW and SW): theoretical, methodological and socio-economic aspects: monograph / M. L. Kazaryan, A. A. Richter, M. A. Shahramanyan, R. D. Nedkov. INFRA-M, 2019. 278 p. + Add. Materials. URL: http://www.znanium.com. DOI:10.12737/monography_5c4efa771779a4.

30. Astsatryan, H., W. Narsisian, and Sh. Asmaryan, SWAT Hydrological Model as a DaaS Cloud Service, Springer Earth Science Informatics, 2016, 1-7, DOI:10.1007/s12145-016-0254-6.

31. Astsatryan, H., W. Narsisian, A. Hayrapetyan, A. Saribekyan, S. Asmaryan, V. Muradyan, Y. Guigoz, G. Giuliani, and N. Ray, An interoperable web portal for parallel geoprocessing of satellite image vegetation indices, Springer Earth Science Informatics, 2015, 8, 2, 453-60, DOI:10.1007/s12145-014-0165-3.

32. Astsatryan, H., W. Narsisian, and G. da Costa, SaaS for Energy Efficient Utilization of HPC Resources of Linear Algebra Calculations, Scalable Computing: Practice and Experience, 2017, 18, 2, 145-50, DOI:10.12694/scpe.v18i2.1284. 


\title{
О ПРОЕКТИРОВАНИИ АВТОМАТИЗИРОВАННОЙ СИСТЕМЫ МОНИТОРИНГА ОБЪЕКТОВ ЗАХОРОНЕНИЯ ОТХОДОВ И В ТОМ ЧИСЛЕ ПРОМЫШЛЕННЫХ С ПРИМЕНЕНИЕМ ТЕХНОЛОГИЙ ДИСТАНЦИОННОГО ЗОНДИРОВАНИЯ ЗЕМЛИ
}

\section{М. Казарян}

\begin{abstract}
Аннотация
В настоящее время геоинформационные системы заняли прочные позиции в области экономики, политики и, практически, всех сфер жизнедеятельности человека. Как следствие человеческой деятельности на урбанизированных территориях - это появление и дальнейшее распространение не санкционированных мусорных свалок и промышленных отходов. Чтобы вовремя вмешаться и остановить распространение очагов инфекции и изменений в почвенном составе территорий и т.д. необходимо иметь автоматизированную систему объектов захоронения и промышленных отходов.

Цель работы - проектирование модели автоматизированной системы мониторинга объектов захоронения отходов и в том числе промышленных с применением технологий дистанционного зондирования земли.

Общая методика исследований. В работе используются современные методы проектирования информационных систем с применением теории баз данных, хранилищ данных, геобаз данных.

Научная новизна. Предлагается модель автоматизированной системы космического мониторинга на наличие объектов захоронения отходов. Дается общая методология построения геоинформационной модели, осуществляю-щей мониторинг территорий на наличие объектов захоронения отходов. Общая методика разработки геобаз данных. Геобазы данных ОЗО представляют собой структуру атрибутивных и географических данных, получаемых в автоматизированном режиме. Дается анализ современных перспектив в создании и работе подобных автоматизированных геоинформационных систем с применением определенных знаний в области сверхбольших, распределенных и открытых архивов данных. В качестве реализации теоретических рассуждений приводится практическая часть по формированию программного, технического и математического обеспечения системы дистанционного мониторинга ОЗО и ПО. Работа в целом носит обзорно-исследовательский характер.
\end{abstract}

